\title{
IMPACT OF TELEVISION COMMERCIALS ON CHILDREN'S ATTITUDES IN BANGLADESH: AN EMPIRICAL STUDY
}

\author{
SYED MD. HASIB AHSAN \\ International Islamic University Chittagong, Bangladesh \\ E-mail: hasib27.ahsan@gmail.com \\ ABDULLAHIL MAMUN \\ International Islamic University Chittagong, Bangladesh \\ E-mail: ahm_economics@yahoo.com \\ MOHAMMAD MASRURUL MOWLA \\ International Islamic University Chittagong, Bangladesh \\ E-mail:mmm_iiuc@yahoo.com
}

\begin{abstract}
This paper aims to analyze the impact of television commercials on children in Bangladesh. Advertising in and around children's program has a significant influence over their attitudes. The study considers four fundamental attributes that reflect children's attitudes based on literature survey, namely- unnecessary purchasing behavior, nature of food consumption, materialism and violence, upon which there is influence of TV advertising. Based on a survey on 410 parents of children aged from 5 to 10, the research finds strong association among the variables. Results of ordinary least square regression analysis, employed to estimate the responsiveness of the attributes mentioned earlier towards exposure to advertising, exhibit that child's unnecessary purchasing is highly responsive to television advertising followed by low nutritional food consumption, materialism and violence, respectively. Furthermore, the research rejects all the null hypotheses stating the absence of relationship between the attributes and exposure to advertising that asserts the positive influence of television commercials on all of those attributes.
\end{abstract}

Keywords: Television Commercials, Children’s Attitudes, Advertising Policies. JEL Classification: M37. 